\title{
How patients experience endocrine therapy for breast cancer: an online survey of side effects, adherence, and medical team support
}

\author{
Maurice J. Berkowitz ${ }^{1}$. Carlie K. Thompson ${ }^{2} \cdot$ Laura T. Zibecchi $^{3} \cdot$ Minna K. Lee $^{2}$ - Elani Streja ${ }^{4}$. Jacob S. Berkowitz ${ }^{5}$ \\ Cachet M. Wenziger ${ }^{4}$. Jennifer L. Baker ${ }^{2} \cdot$ Maggie L. DiNome $^{2} \cdot$ Deanna J. Attai $^{2,6}$ (D)
}

Received: 31 March 2020 / Accepted: 14 June 2020 / Published online: 17 August 2020

(C) Springer Science+Business Media, LLC, part of Springer Nature 2020

\begin{abstract}
Purpose Many patients with hormone receptor-positive (HR+) breast cancer do not adhere to endocrine therapy (ET), and treatment-related side effects are often discussed by participants in online breast cancer forums. Our aim was to survey this unique group of patients about their ET-related experiences.

Methods We partnered with patients active in breast cancer social media communities to develop a survey assessing ET-related side effects and medical team communication. Patients with a history of HR+ breast cancer who had received a recommendation to take ET were eligible to participate in the anonymous, online survey.

Results Respondents included 2353 women and 54 men. Aromatase inhibitors were the most commonly used medication. Side effects were reported by $91.2 \%$, were more often experienced by women than men $(p<0.001)$, and were primarily related to medication type. Approximately one-third of respondents discontinued therapy early. While most felt supported by their medical team, $31.5 \%$ reported that their side effects were dismissed or minimized. Survey respondents most frequently reported that a healthy diet and exercise, yoga/acupuncture, and vitamins/supplements were helpful in managing ET-related side effects.

Conclusions ET-related side effects are very common, and one-third discontinued treatment early. Lifestyle changes and complementary therapies can be important tools for side effect management. One-third of patients did not feel that their side effects were taken seriously.

Implications for Cancer Survivors This is the largest survey of ET use by participants in online breast cancer communities. Further research is needed to identify strategies to improve treatment adherence and to better manage ET-related side effects.
\end{abstract}

Keywords Breast cancer $\cdot$ Endocrine therapy $\cdot$ Tamoxifen $\cdot$ Side effects $\cdot$ Aromatase inhibitors

Electronic supplementary material The online version of this article (https://doi.org/10.1007/s11764-020-00908-5) contains supplementary material, which is available to authorized users.

Deanna J. Attai

dattai@mednet.ucla.edu

1 Department of Medicine, David Geffen School of Medicine, University of California Los Angeles, Los Angeles, USA

2 Department of Surgery, David Geffen School of Medicine, University of California Los Angeles, Los Angeles, USA

3 Department of Nursing, University of California Los Angeles, Los Angeles, USA

4 Department of Medicine, University of California Irvine School of Medicine, Irvine, USA

5 Dietrich School of Arts and Sciences, University of Pittsburgh, Pittsburgh, USA

6 UCLA Health Burbank Breast Care, 191 S. Buena Vista \#415, Burbank, CA 91505, USA

\section{Introduction}

The majority of invasive breast cancers are hormone receptorpositive (HR+) [1-5]. Endocrine therapy (ET), a key component of breast cancer treatment, reduces the risk of local and distant recurrence $[2,6-8]$. The recommended duration of adjuvant ET for early-stage breast cancer (ES-BC, used in this paper to refer to stages $0-3$ ) is 5 years, although it may be extended to 10 years in select high-risk patients [7,8]. ET is also utilized as primary therapy for many patients diagnosed with HR+ metastatic breast cancer (Met-BC) [5, 8], a condition that requires some form of lifelong treatment.

Despite the known efficacy of ET, up to $30 \%$ of patients with invasive $\mathrm{HR}+$ breast cancer who are prescribed ET never initiate therapy [9]. In addition, $18 \%$ to $73 \%$ of patients who initiate ET do not complete the prescribed course of treatment $[2,4,6,9-19]$. Early discontinuation of therapy is associated 
with increased recurrence and breast cancer-specific mortality rates, as well as higher medical costs $[2,9,11,18-21]$. Therefore, it is crucial to understand barriers to ET adherence.

A growing number of patients participate in online support groups and discussion boards that focus on various aspects of medical care. Patients with breast cancer are more likely than those with other cancers to participate in such forums [22-29]. Common discussion topics include medication side effects and medical team interactions. Therefore, we sought to survey this unique group of patients about their experiences with ET. Our objectives were to characterize reasons for not initiating treatment, to describe patient-reported ET-related side effects and side effect management, and to investigate the impact of the patient-medical team relationship on medication adherence.

\section{Methods}

\section{Survey development and administration}

The motivation for this study came from conversations among patients who discuss ET and other aspects of their breast cancer care in online communities. Unique features of this work include the use of a survey designed with patient input and distribution of the survey using social media platforms, as well as the aims of evaluating self-reported side effect management strategies and effectiveness, and evaluating the patient experience in discussing side effects with their medical team.

Nine patient advocates ( 6 women and 3 men) were chosen based on their personal history of ES-BC or Met-BC, current or prior ET use, advocacy and research experience, and activity within breast cancer social media communities. Existing survey tools were reviewed, but as has been demonstrated in prior work [30], the advocates felt that no existing survey covered all pertinent issues. An original survey was therefore developed based in part on a conceptual framework of decisional support and decisional needs [31]. The patient advocates and eight medical experts contributed to survey development (Appendix Figure 1).

The Institutional Review Board of the University of California, Los Angeles granted approval to distribute a survey link to online breast cancer communities. The SurveyMonkey® tool was configured to be anonymous and to preclude repeat complete surveys from the same internet protocol address. All 33 questions required a response, and 13 questions allowed for open-ended comments. The survey was provided in English, and there was no financial or other type of incentive for participation. Four of the patient advocates pre-tested the survey prior to distribution. A link to the survey was posted on the senior author's (DJA) personal blog and Facebook and Twitter accounts, and it was shared by the Dr. Susan Love Research Foundation Army of Women (currently known as the Love Research Army) email newsletter and social media accounts. We then relied on interested parties to share the survey within their social media networks. The survey was open from May 12 to July 14, 2019.

\section{Statistical analyses}

Characteristics and responses by survey participants were described using mean ( \pm standard deviation), median (interquartile range [IQR]), and percentage according to the data distribution and type. Comparisons between respondents' sex and ES-BC versus Met-BC status were conducted using $t$ test, Mann-Whitney $U$, and chi-square statistics or Fisher's exact test, as appropriate. Additional comparisons of question responses were conducted using a chi-square test for $p$ values and logistic regression analysis for odds ratios. Effect modification of menopausal status on the age-adjusted association of tamoxifen-only versus aromatase inhibitor (AI)-only with reported side effects was evaluated with Wald's tests for interaction. All analyses were conducted in STATA version 13.0 (Stata Corporation, College Station, TX).

\section{Results}

\section{Respondents and demographics}

Of 2994 survey respondents, 95 were excluded for study criteria ineligibility, which included no history of breast cancer, HR-negative breast cancer, or no recommendation for ET from their medical team. An additional 381 were excluded due to incomplete surveys, discrepancies in responses, or inability to determine whether hormonal therapy for gender reassignment was administered. Of the remaining 2518 respondents, $4.4 \%$ (111/2518) reported that ET was recommended but they did not initiate treatment. These patients are characterized, but not included in the main analysis, leaving a final analytical cohort of 2407 respondents who initiated ET (Appendix Figure 2).

The final cohort of 2407 respondents included 54 men (2.2\%) and 2353 women (97.8\%). At the time of first breast cancer diagnosis, $25.6 \%(602 / 2353)$ of the women were premenopausal and $74.3 \%$ (1748/2353) were postmenopausal; three respondents did not remember their menopausal status. Respondents' ages ranged from 24 to 86 years. Age at diagnosis ranged from 23 to 82 years among female respondents, and from 24 to 73 years among male respondents. Most respondents $(87.0 \%, 2093 / 2407)$ had been diagnosed with stage 1-3 disease. One hundred $(4.2 \%, 100 / 2407)$ were diagnosed at stage 4 , with de novo metastatic breast cancer. Of those initially diagnosed with ES-BC, $11.7 \%$ of patients (270/ 2307) developed Met-BC during the course of their treatment, $11.5 \%$ of women $(260 / 2255)$, and $19.2 \%$ of men $(10 / 52)$. Additional demographic information is provided in Table 1. 


\section{Treatment initiation and discontinuation}

Among the 111 respondents who did not start ET as recommended (multiple selections permitted), concern about potential side effects was the most commonly expressed reason for not initiating therapy $(92.8 \%, 103 / 111)$. Other reasons included concerns about impact on general health or other health conditions $(80.2 \%, 89 / 111)$, perceived benefits not outweighing perceived risks $(67.6 \%, 75 / 111)$, concerns about secondary cancers $(49.5 \%, 55 / 111)$, desire to avoid taking a prescription medication $(19.8 \%, 22 / 111)$, and cost $(3.6 \%$, $4 / 111)$. Two respondents (1.8\%) did not initiate therapy because they anticipated becoming pregnant.

Among the entire cohort who initiated therapy, 8.8\% (213/ 2407) reported that they took treatment breaks or discontinued therapy early either against the advice or without informing their medical team. Nine respondents took a treatment break or discontinued early because they intended to become pregnant.

Overall, 33.2\% (799/2407) of patients discontinued therapy early, which included $32.8 \%$ (772/2353) of women and $50.0 \%(27 / 54)$ of men $(p=0.008)$. US residents were more likely to discontinue ET early compared with non-US residents $(34.7 \%, 663 / 1912$ versus $27.5 \%, 136 / 495 ; p=0.002)$. Those who did not have a college degree were more likely to discontinue early compared with those who had a college degree $(37.3 \%, 218 / 585$ versus $31.9 \%, 581 / 1822 ; p=$ 0.016 ). Respondents who discontinued early were fairly evenly distributed by stage at diagnosis (stage $0,35.1 \%, 71 / 202$; stages 1-3, 33.3\%, 698/2093; stage 4, 26.0\%, 26/100; did not remember stage, $33.3 \%, 4 / 12$ ).

\section{Medication type, duration, and side effects}

Medication use and duration of therapy are shown in Table 2. Respondents were asked to select all ET agents they had used. Aromatase inhibitors (AIs) were the most commonly used medication, followed by tamoxifen; 26.6\% (640/2407) took both tamoxifen and an $\mathrm{AI}$ at some point in their treatment. Most respondents $(78.4 \%, 1888 / 2407)$ were current users of ET, and of this group, $15.7 \%$ (296/1888) reported currently living with Met-BC.
Table 1 Survey respondent demographic characteristics

\begin{tabular}{|c|c|c|c|}
\hline Characteristics & $\begin{array}{l}\text { All respondents } \\
(n=2407)\end{array}$ & $\begin{array}{l}\text { Women } \\
(n=2353,97.8 \%)\end{array}$ & $\begin{array}{l}\text { Men } \\
(n=54,2.2 \%)\end{array}$ \\
\hline \multicolumn{4}{|l|}{ Menopausal status of 2353 women (\%) } \\
\hline Premenopausal & & $602(25.6)$ & \\
\hline Postmenopausal & & $1748(74.3)$ & \\
\hline Does not remember & & $3(0.13)$ & \\
\hline Current age (mean (SD)) & & $56(10)$ & $59(9)$ \\
\hline Age at diagnosis (mean (SD)) & & $50(10)$ & $54(9)$ \\
\hline \multicolumn{4}{|l|}{ Education $(\%)$} \\
\hline High school degree or less & $171(7.1)$ & $167(7.1)$ & $4(7.4)$ \\
\hline Some college but no degree & $414(17.2)$ & $402(17.1)$ & $12(22.2)$ \\
\hline Associate's or bachelor's degree & $1011(42.0)$ & $982(41.7)$ & $29(53.7)$ \\
\hline Graduate degree & $811(33.7)$ & $802(34.1)$ & $9(16.7)$ \\
\hline \multicolumn{4}{|l|}{ Nationality (\%) } \\
\hline USA & $1912(79.4)$ & $1867(79.3)$ & $45(83.3)$ \\
\hline UK & $215(8.9)$ & $215(9.1)$ & 0 \\
\hline Canada & $152(6.3)$ & $148(6.3)$ & $4(7.4)$ \\
\hline Other & $128(5.3)$ & $123(5.3)$ & $5(9.3)$ \\
\hline \multicolumn{4}{|l|}{ Stage at diagnosis $(\%)$} \\
\hline 0 & $202(8.4)$ & $199(8.5)$ & $3(5.6)$ \\
\hline I-III & $2093(87.0)$ & $2044(86.9)$ & $49(90.7)$ \\
\hline IV & $100(4.2)$ & $98(4.2)$ & $2(3.7)$ \\
\hline Does not remember & $12(0.5)$ & $12(0.5)$ & 0 \\
\hline Currently living with metastatic disease & $370(15.4)$ & $358(15.2)$ & $12(22.2)$ \\
\hline
\end{tabular}

$S D$, standard deviation 
Medication side effects are shown in Table 3. At least one class of side effects attributed to ET was reported by $91.2 \%$ (2194/2407) of respondents, including 91.5\% (2152/2353) of women and $74.1 \%(40 / 54)$ of men $(p<0.001)$. Among patients with ES-BC, $91.6 \%(1866 / 2037)$ reported at least one class of side effect versus $88.6 \%$ (328/370) of those with Met$\mathrm{BC}(p=0.065)$.

Among women with both ES-BC and Met-BC, the most commonly reported side effects were musculoskeletal and general physical changes (such as weight gain and unhappiness with body image). Among men with ES-BC, sexual and cognitive/mood side effects were most commonly reported. Among men with Met-BC, sexual, cognitive/mood, and musculoskeletal side effects were noted with equal frequency.
Concerns about medication cost were reported by $5.4 \%$ (130/2407) of respondents (Table 3).

For women with ES-BC, odds of reporting side effects differed significantly according to the class of medication (tamoxifen-only versus AI-only) in age-adjusted models. Menopausal status did not independently influence this association (Fig. 1). Odds of reporting cardiac/vascular and musculoskeletal side effects, as well as concerns about medication cost, were higher in AI-only users than in tamoxifen-only users. Medication class was not associated with odds of reporting sexual, vasomotor, cognitive / mood, general physical, visual, gastrointestinal, or genitourinary side effects. We found no differences in odds of reporting side effects based on medication
Table 2 Medication use and duration

\begin{tabular}{|c|c|c|c|c|c|}
\hline Variable & $\begin{array}{l}\text { All patients } \\
(n=2407)\end{array}$ & $\begin{array}{l}\text { W-ES } \\
(n=1995)\end{array}$ & $\begin{array}{l}\text { W-Met } \\
(n=358)\end{array}$ & $\begin{array}{l}\text { M-ES } \\
(n=42)\end{array}$ & $\begin{array}{l}\text { M-Met } \\
(n=12)\end{array}$ \\
\hline \multicolumn{6}{|c|}{ Type of endocrine therapy (\%) } \\
\hline Tamoxifen* & $1277(53.1)$ & $1033(51.8)$ & $194(54.2)$ & $38(90.5)$ & $12(100.0)$ \\
\hline Tamoxifen-only & $578(24.0)$ & $514(25.8)$ & $23(6.4)$ & $35(83.3)$ & $6(50.0)$ \\
\hline $\begin{array}{l}\text { Tamoxifen }+ \\
\text { AI* }^{*}\end{array}$ & $640(26.6)$ & $471(23.6)$ & $160(44.7)$ & $3(7.1)$ & $6(50.0)$ \\
\hline Raloxifene & $14(0.6)$ & $11(0.6)$ & $3(0.8)$ & 0 & 0 \\
\hline Any type of AI & $1747(72.6)$ & $1422(71.3)$ & $312(87.2)$ & $7(16.7)$ & $6(50.0)$ \\
\hline Anastrozole* & $1057(43.9)$ & $906(45.4)$ & $142(39.7)$ & $5(11.9)$ & $4(25.0)$ \\
\hline Exemestane* & $488(20.3)$ & $388(19.4)$ & $99(27.7)$ & $1(2.4)$ & 0 \\
\hline Letrozole* & $858(35.7)$ & $635(31.8)$ & $217(60.6)$ & $1(2.4)$ & $5(41.7)$ \\
\hline AI-only & 949 (39.4) & $855(42.9)$ & $90(25.1)$ & $4(9.5)$ & 0 \\
\hline Fulvestrant & $127(5.3)$ & $118(5.9)$ & $7(2.0)$ & 0 & $2(16.7)$ \\
\hline Leuprolide & $281(11.7)$ & $208(10.4)$ & $72(20.1)$ & 0 & $1(8.3)$ \\
\hline \multicolumn{6}{|l|}{ Current ET use (\%) } \\
\hline$<5$ years & $1464(60.8)$ & $1277(64.0)$ & $160(44.7)$ & $21(50.0)$ & $6(50.0)$ \\
\hline 5 years & $92(3.8)$ & $74(3.7)$ & $16(4.5)$ & $2(4.8)$ & 0 \\
\hline 5 to 10 years & $282(11.7)$ & $186(9.3)$ & $85(23.7)$ & $9(21.4)$ & $2(16.7)$ \\
\hline$>10$ years & $49(2.0)$ & $21(1.1)$ & $27(7.5)$ & $1(2.4)$ & 0 \\
\hline $\begin{array}{l}\text { I do not } \\
\text { remember }\end{array}$ & $1(0.04)$ & $1(0.05)$ & 0 & 0 & 0 \\
\hline \multicolumn{6}{|l|}{ Prior ET use (\%) } \\
\hline$<5$ years & 287 (11.9) & $248(12.4)$ & $31(8.7)$ & $4(9.5)$ & $4(25.0)$ \\
\hline 5 years & $118(4.9)$ & $103(5.1)$ & $11(3.1)$ & $4(9.5)$ & 0 \\
\hline 5 to 10 years & $93(3.9)$ & $72(3.6)$ & $21(5.9)$ & 0 & 0 \\
\hline$>10$ years & $21(0.9)$ & $13(0.6)$ & $7(2.0)$ & $1(2.4)$ & 0 \\
\hline
\end{tabular}

$A I$ aromatase inhibitor, $E T$ endocrine therapy

*Multiple selections permitted

$W$-ES women, early stage

W-Met women, metastatic

$M-E S$ men, early stage

M-Met men, metastatic 
Table 3 Medication side effects

\begin{tabular}{|c|c|c|c|c|c|c|c|c|}
\hline Variable & $\begin{array}{l}\text { All patients } \\
(n=2407)\end{array}$ & $\begin{array}{l}\text { W-ES } \\
(n=1995)\end{array}$ & $\begin{array}{l}\text { W-Met } \\
(n=358)\end{array}$ & $\begin{array}{l}\text { M-ES } \\
(n=42)\end{array}$ & $\begin{array}{l}\text { M-Met } \\
(n=12)\end{array}$ & $\begin{array}{l}\text { Chi-square } p \text { value: } \\
\text { M-ES versus W-ES }\end{array}$ & $\begin{array}{l}\text { Chi-square } p \text { value: } \\
\text { W-ES versus W-Met }\end{array}$ & $\begin{array}{l}\text { Chi-square } p \text { value: } \\
\text { M-Met versus W-Met }\end{array}$ \\
\hline \multicolumn{9}{|l|}{ Reported side effects $(\%)^{*}$} \\
\hline Any & $2194(91.2)$ & $1835(92.0)$ & $319(89.1)$ & $31(73.8)$ & $9(75.0)$ & $<0.001$ & 0.072 & 0.130 \\
\hline Cardiovascular & $309(12.8)$ & $262(13.1)$ & $41(11.5)$ & $3(7.1)$ & $3(25.0)$ & 0.253 & 0.382 & 0.154 \\
\hline Cognitive/mood & $1515(62.9)$ & $1282(64.3)$ & $205(57.3)$ & $21(50.0)$ & $7(58.3)$ & 0.057 & 0.011 & 0.941 \\
\hline Eyes & $798(33.2)$ & $654(32.8)$ & $132(36.9)$ & $10(23.8)$ & $2(16.7)$ & 0.22 & 0.131 & 0.152 \\
\hline $\begin{array}{l}\text { General physical } \\
\text { changes }\end{array}$ & $1652(68.6)$ & $1381(69.2)$ & $248(69.3)$ & $17(40.5)$ & $6(50.0)$ & $<0.001$ & 0.985 & 0.157 \\
\hline Gastrointestinal & $629(26.1)$ & $514(25.8)$ & $109(30.4)$ & $3(7.1)$ & $3(25.0)$ & 0.006 & 0.064 & 0.686 \\
\hline Genitourinary & 945 (39.3) & $812(40.7)$ & $128(35.8)$ & $4(9.5)$ & $1(8.3)$ & 0.05 & 0.078 & $<0.001$ \\
\hline Musculoskeletal & $1788(74.3)$ & $1488(74.6)$ & $278(77.7)$ & $15(35.7)$ & $7(58.3)$ & $<0.001$ & 0.217 & 0.118 \\
\hline Sexual & 1314 (54.6) & $1087(54.5)$ & $199(55.6)$ & $21(50.0)$ & $7(58.3)$ & 0.563 & 0.700 & 0.035 \\
\hline Vasomotor & $1461(60.7)$ & $1231(61.7)$ & $207(57.8)$ & $17(40.5)$ & $6(50.0)$ & 0.005 & 0.165 & 0.590 \\
\hline High cost of medication & $129(5.4)$ & $95(4.8)$ & $34(9.5)$ & 0 & 0 & 0.148 & $<0.001$ & 0.263 \\
\hline
\end{tabular}

$A I$ aromatase inhibitor, $E T$ endocrine therapy

*Multiple selections permitted

$W$-ES women, early stage

W-Met women, metastatic

$M$-ES men, early stage

$M$-Met men, metastatic

class in respondents with ES-BC versus Met-BC (Appendix Table 1).

\section{Side effect management}

Survey respondents most frequently reported that three groups of management strategies were helpful for ETrelated side effects: a healthy diet, exercise, and physical therapy; complementary therapy such as yoga, acupuncture, and meditation; and vitamins, supplements, and herbs including medical marijuana. Some respondents felt that peer-to-peer support $(19.9 \%, 478 / 2407)$ or websites with information about endocrine therapy $(9.6 \%, 230 / 2407)$ were helpful, but the medical team was less likely to recommend these resources. For patients with ES-BC and Met-BC, there were only a few significant differences in suggestions for side effect management received by the medical team versus family/friends/internet. ES-BC and Met-BC patients experienced the same rates of side effect relief from the different management recommendations (Appendix Table 2). Among both ES-BC and Met-BC patients, those who felt supported by their medical team were more likely to receive a higher median number of side effect management recommendations from their medical team compared with patients who did not feel supported (2 [IQR 1,4] versus 0 [IQR 0,1$], p<0.001)$.

\section{Medical team communication}

The majority of patients reported that they understood the goals of therapy, concordant with their stage of disease. For example, respondents with Met-BC at diagnosis had increased odds of reporting the goal of therapy as "controlling spread," compared with those with ES-BC (OR 107, 95\% CI [47, 247] $p<0.001)$. Patients who stopped treatment early and those who took the full course of therapy were similar in their understanding of the goals of therapy (Appendix Table 3).

The majority of patients who experienced side effects reported discussing or attempting to discuss them with their medical team (ES-BC 92.8\%, 1732/1866 and Met-BC $91.8 \%, 301 / 328)$. Respondents were most likely to discuss management of side effects with their oncology physicians (79.0\%, 1902/2407) versus (multiple selections permitted) other oncology team members such as nurse practitioners $(33.6 \%, 809 / 2407)$, primary care providers $(36.8 \%, 885 /$ 2407), or other medical specialists (12.3\%, 296/2407). Additional information regarding support and side effect management recommendations by medical team category is provided in Appendix Table 4.

In characterizing medical team discussions (multiple selections permitted, and 2 patients characterized discussions without indicating a side effect), $70.0 \%(68.8 \%, 1193 / 1734$ with ES-BC compared with $77.4 \%, 233 / 301$ with Met-BC) felt supported by their medical team $(p=0.003)$. However, 


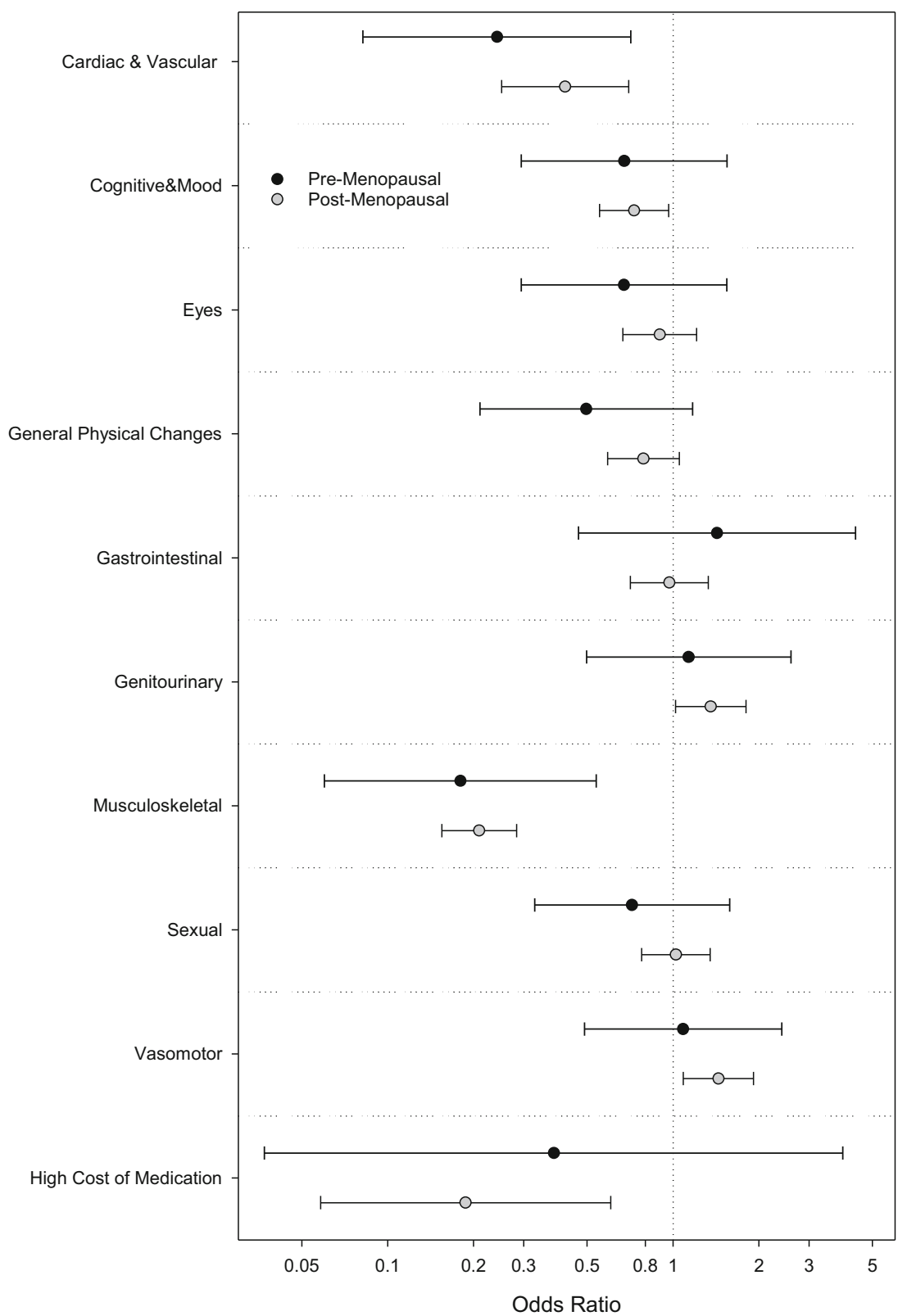

Fig. 1 Age-adjusted odds of side effects in women who received tamoxifen-only compared with AI-only

$31.5 \%(33.2 \%, 575 / 1734$ with ES-BC and $22.3 \%, 67 / 301$ with Met-BC) stated that they were made to feel as though they should be better able to handle side effects on their own, or that their side effects were not related to treatment, or both $(p=<0.001)$. A small number of patients, $6.6 \%(6.4 \%, 120 / 1866$ with ES-BC and $7.6 \%$, $25 / 328$ with Met-BC, $p=0.424$ ), did not discuss or attempt to discuss side effects with their medical team, noting that there were more important issues to discuss, that there was not enough time, or that they did not feel comfortable.

When respondents were asked to offer advice or suggestions for how the medical team could help a patient feel more supported or could assist with side effect management (multiple selections permitted), the most-selected option was referral to a website with information about side effects and how to manage them, followed by a specific office visit (inperson or virtual) to discuss medication side effects. Other recommendations included access to an oncology social worker, peer support (in-person or virtual), an app to track and report side effects to the medical team, and access to a financial counselor (Appendix Table 5). Survey respondents expressed frustration about side effects not being taken seriously and about a lack of effective side effect management strategies. Some representative comments include: "Yes, these are COMMON side effects - can you handle it?"; "I felt dismissed, I don't think they felt my complaints were that big a deal"; and "I felt comfortable discussing with doctors, 
but at the end I felt like there's nothing that can be done to help my symptoms.'

\section{Discussion}

This is the largest survey of ET use by patients who participate in online breast cancer communities. We demonstrate that social media can be effective in rapidly obtaining large numbers of patient responses regarding care issues. Similar to previous studies [1, 7, 10, 17-19, 34-39], our results demonstrate that most patients $(91 \%)$ who take ET experience related side effects, and one-third discontinue treatment early. Our findings suggest that online patient communities can be a valuable tool for identifying variables that influence breast cancer patients' adherence to ET.

We found that most patients understood the goals of therapy; however, this understanding was not associated with a higher likelihood of completing treatment. This suggests that understanding of the importance of therapy may not be sufficient for adherence when patients face medication-related side effects that significantly interfere with quality of life. While medical team support and communication are important factors influencing ET adherence [6, 9, 14, 40-45], we did not find that feeling "supported" by the medical team was associated with improved medication adherence. A very low number of survey respondents reported financial concerns related to ET or as a reason for discontinuing therapy. In contrast, previous studies have found associations between socioeconomic status, out-of-pocket medication costs, and ET adherence [46, 47]. Our finding may be related to the widespread availability of generic formulations or that participants in online patient communities are more likely to be of higher socioeconomic status compared with the general population [48-51]. Despite low reported concerns about medication cost, we found similar rates of early discontinuation as have studies evaluating adherence based on socioeconomic status [47].

The responses to our survey demonstrate the many nuances of ET-related side effects and challenges with adherence faced by patients. Respondents to our survey provided many suggestions that would make them feel more supported or would help them to better manage side effects. Most of these centered on communication including dedicated office visits and the ability to report side effects, as well as peer support. It is important that one-third of our survey respondents felt that their medical team did not take their side effects seriously. Patients and their medical team members might have differing perspectives on the definition of a "well-tolerated" medication and on measures of quality of life [52, 53], but efforts must be made to better understand the patient's point of view. There are a variety of conceptual framework models such as decision support and needs, symptom management, symptom experience, self-management, and patient activation [31, 53-56] that can be applied to improve adherence $[57,58]$. For example, a recent pilot program demonstrated that patient activation did not improve oral oncolytic adherence; however, patients who completed the program did report increased confidence in their ability to self-manage symptoms and seek help when experiencing side effects [55]. Although these conceptual framework models may be used to guide interventions, our study provides patient-driven recommendations about improving medical team support of patients who experience medication-related side effects and can serve as areas of future study.

In a recent nationwide survey of oncology patients, respondents reported being more likely to stop therapy if they experienced unexpected side effects, and approximately one-third said they wished they had known more about treatment toxicities [59]. This demonstrates the importance of continued and serial communication between the medical team and the patient. Overcoming the burden of numerous in-office visits, the increase in successful telehealth visits during the COVID19 pandemic [60] has demonstrated that virtual platforms can be a means for these discussions. An in-person or virtual visit just prior to treatment initiation could overcome the finding that many patients do not remember having detailed discussions about potential ET-related side effects and may serve to reinforce that ET is just as important a component of treatment as surgery, chemotherapy, or radiation therapy [20, 30, 61]. Intermittent telehealth visits could also address patient decision resolve, as many patients re-visit their commitment to continue ET multiple times throughout the course of treatment [2]. Patients may benefit from repeated review of both medication benefits, focusing on absolute, rather than relative benefit, as well as the impact on quality of life during the course of therapy $[2,5,18,19,34,37,42,43,62,63]$, in a way that more passive reminders do not address.

As our survey respondents reported that diet, exercise, and physical therapy were among the most helpful side effect management strategies, providing nutrition and exercise counseling prior to ET initiation may help improve a patient's treatment experience. However, less than half of the respondents felt that any interventions were helpful. This suggests that offering varied and more personalized suggestions for side effect management could improve patients' experience with ET. Areas for future study may include medical team education on non-prescription resources including interactive educational and side effect reporting and management tools, peer support, and complementary therapies.

We found that patients with ES-BC and Met-BC experience similar side effects and have comparable side effect management experiences. Despite their similarity in responses to this survey, patients with Met-BC clearly have a different experience with different supportive needs compared with those with ES-BC [64-66]. Patients with Met-BC may be on some 
form of endocrine therapy for life, often in combination with other agents. Frequency and severity of side effects that impact quality of life may go under-reported and therefore undertreated in this patient population [67]. One respondent noted "When I was early stage I stopped anastrozole after nine months due to severe arthralgia that interfered with my career. Now that I am metastatic I take my exemestane every day, regardless of symptoms" and another stated that "Side effects mean nothing if it is saving my life." Attention to quality of life either through the expanded use of specific patientreported outcomes or other measures [66-68] on a regular basis is especially important in this patient population.

Our study adds to what is known about the experience of men with breast cancer who are prescribed ET [15, 69-73]. Compared with women, men in our study were less likely to report side effects but more likely to discontinue therapy. Interestingly, prior work has demonstrated that men are more likely compared with women to adhere to medications for myocardial infarction, hypertension, and other chronic conditions [74-76]. More work is needed to better understand ETrelated side effects and factors associated with mediation adherence in men. There remains a lack of peer and emotional support specific to men, with one male respondent commenting, "I am a male going through this. I sometimes feel very alone in my situation." The ongoing International Male Breast Cancer Program [70, 77] is expected to provide additional information on male breast cancer biology, outcomes, and quality of life, as well as recommendations for optimal treatment and supportive care.

Our study has several limitations. As with any survey distributed over social media, the results are biased by the scope of survey respondents, and we cannot estimate the extent to which this respondent pool represents the experience of all patients taking endocrine therapy. Participants in online patient communities are more likely to be white, younger, college-educated, and of higher socioeconomic status than the general patient population $[52,54,55,78]$, so our findings may not apply to a more diverse population, and this should be a focus of future work [79]. We did not ask about baseline symptoms or prior/ concomitant therapy, which could impact how patients with both ES-BC and Met$\mathrm{BC}$ experience ET [36, 37, 68]. We do not know if participants stopped treatment early due to severity of side effects, ability to manage side effects, or other reasons. We did not have the ability to access medical records to confirm patient-reported stage, medication use, and other factors. Finally, we did not use a validated survey tool, although not all validated patient-reported outcome survey tools accurately reflect the patient experience [80]. We designed our survey with the input of breast cancer patient advocates, including men and women with different disease stages and care experiences, in an attempt to address issues that were important to them.
Strengths of our study include a large number of respondents, most of whom were within their first 5 years of treatment, reflecting contemporary ET use and a low likelihood of recall bias. This unique online patient population is engaged in their healthcare and is comfortable using their own treatment experiences to help others. These patients are also experienced in interacting with the medical community as partners in education and research, as evident from their engagement with survey design and distribution.

\section{Conclusions}

Most breast cancer patients who initiated ET reported treatment-related side effects. Concern about side effects was the most common reason for not initiating therapy, and approximately one-third of those who initiated therapy did not complete the full treatment course. Approximately one-third reported feeling dismissed or not taken seriously when trying to discuss side effects and the impact of ET on quality of life with their healthcare team.

At most, only $41 \%$ of patients experienced side effect relief, demonstrating that more effective strategies for managing ET-related side effects are needed. In addition, while we have shown that social media is effective for obtaining information on the patient experience, further studies must identify the optimal ways to solicit and interpret patient-reported outcomes from this rapidly growing patient population.

Acknowledgments The authors wish to acknowledge and thank the following physicians and patient advocates who reviewed and contributed to the survey: Dr. Oliver Bogler, Terri Coutee, Dr. Patricia Ganz, Dr. Julie Gralow, Kathy Gori, Dr. Sarah Hawley, Dennis Keim, Dr. Susan Love, AnneMarie Mercurio, Rod Ritchie, Dr. Kelly Shanahan, Alicia Staley, and Nancy Stordahl. We would like to thank Dr. Patricia Ganz for her review of the manuscript. In addition, we would like to thank all who distributed the survey and all who participated.

\section{Compliance with ethical standards}

Conflict of interest The authors declare that they have no conflict of interest.

\section{References}

1. Awan A, Esfahani K. Endocrine therapy for breast cancer in the primary care setting. Curr Oncol. 2018;25(4):285-91.

2. Beryl LL, Rendle KA, Halley MC, et al. Mapping the decisionmaking process for adjuvant endocrine therapy for breast cancer: the role of decisional resolve. Med Decis Mak. 2017;37(1):79-90.

3. Joe BN. Clinical features, diagnosis, and staging of newly diagnosed breast cancer. In: UpToDate. Burstein H, Vora SR (eds.). Waltham, MA: UpToDate, 2019. https://www.uptodate.com/ contents/clinical-features-diagnosis-and-staging-of-newlydiagnosed-breast-cancer Accessed 31 May 2020. 
4. Kadakia KC, Kidwel KM, Barton DL, Schott AF, Hayes DF, Griggs JJ, et al. Factors influencing the use of extended adjuvant endocrine therapy. Breast Cancer Res Treat. 2019;175(1):181-9.

5. Rugo HS, Rumble RB, Macrae E, Barton DL, Connolly HK, Dickler MN, et al. Endocrine therapy for hormone receptorpositive metastatic breast cancer: American Society of Clinical Oncology guideline. J Clin Oncol. 2016;34(25):3069-103.

6. Bluethmann SM, Murphy CC, Tiro JA, Mollica MA, Vernon SW, Bartholomew LK. Deconstructing decisions to initiate, maintain or discontinue adjuvant endocrine therapy in breast cancer survivors: a mixed-methods study. Oncol Nurs Forum. 2017;44(3):E101-10.

7. Burstein HJ, Lacchetti C, Anderson H, Buchholz TA, Davidson $\mathrm{NE}$, Gelmon KA, et al. Adjuvant endocrine therapy for women with hormone receptor-positive breast cancer: ASCO clinical practice guideline focused update. J Clin Oncol. 2019;37(5):423-38.

8. National Comprehensive Cancer Network Clinical Practice Guidelines in Oncology: Breast Cancer version 4.2020. https:// www.nccn.org Accessed 31 May 2020.

9. Chlebowski RT, Kim J, Haque R. Adherence to endocrine therapy in breast cancer adjuvant and prevention settings. Cancer Prev Res (Phila). 2014;7(4):378-87.

10. Aiello Bowles EJ, Boudreau DM, Chubak J, Yu O, Fujii M, Chestnut J, et al. Patient-reported discontinuation of endocrine therapy and related adverse effects among women with early stage breast cancer. J Oncol Pract. 2012;8(6):e149-57.

11. Harrow A, Dryden R, McCowan C, Radley A, Parsons M, Thompson AM, et al. A hard pill to swallow: a qualitative study of women's experiences of adjuvant endocrine therapy for breast cancer. BMJ Open. 2014;4(6):e005285. https://doi.org/10.1136/ bmjopen-2014-005285.

12. Henry NL, Azzouz F, Desta Z, Li L, Nguyen AT, Lemler S, et al. Predictors of aromatase inhibitor discontinuation as a result of treatment-emergent symptoms in early-stage breast cancer. J Clin Oncol. 2012;30(9):936-42.

13. Hershman DL, Kushi LH, Shao T, Buono D, Kershenbaum A, Tsai WY, et al. Early discontinuation and nonadherence to adjuvant hormonal therapy in a cohort of 8,769 early-stage breast cancer patients. J Clin Oncol. 2010;28(27):4120-8.

14. Lambert LK, Balneaves LG, Howard AF, Gotay CC. Patientreported factors associated with adherence to adjuvant endocrine therapy for breast cancer: an integrative review. Breast Cancer Res Treat. 2018a;167(3):615-33.

15. Oke O, Niu J, Chavez-MacGregor M, Zhao H, Giordano SH. Adjuvant tamoxifen adherence in men with early stage breast cancer. J Clin Oncol. 2018;36(15 suppl):550 https://ascopubs.org/doi/ abs/10.1200/JCO.2018.36.15_suppl.550.

16. Partridge AH, Wang PS, Winer EP, Avorn J. Nonadherence to adjuvant tamoxifen therapy in women with primary breast cancer. J Clin Oncol. 2003;21(4):602-6.

17. Rosenberg SM, Stanton AL, Petrie KJ, Partridge AH. Symptoms and symptom attribution among women on endocrine therapy for breast cancer. Oncologist. 2015;20(6):598-604.

18. van Hellemond IEG, Geurts SME, Tjan-Heijnen VCG. Current status of extended adjuvant endocrine therapy in early stage breast cancer. Curr Treat Options in Oncol. 2018;19(5):26. https://doi.org/ 10.1007/s11864-018-0541-1.

19. Wen KY, Smith R, Padmanbhan A, Goldstein L. Patient experience of taking adjuvant endocrine therapy for breast cancer: a tough pill to swallow. Patient Exp J. 2017;4(3). https://doi.org/10.35680/ 2372-0247.1173.

20. van Londen GJ, Donovan HS, Beckjord EB, Cardy AL, Bovbjerg DH, Davidson NE, et al. Perspectives of postmenopausal breast cancer survivors on adjuvant endocrine therapy-related symptoms. Oncol Nurs Forum. 2014;41(6):660-8.

21. Walker HE, Rosenberg SM, Stanton AL, Petrie KJ, Partridge AH. Perceptions, attributions, and emotions toward endocrine therapy in young women with breast cancer. J Adolesc Young Adult Oncol. 2016;5(1):16-23.

22. Attai DJ, Cowher MS, Al-Hamadani M, Schoger JM, Staley AC, Landercasper J. Twitter social media is an effective tool for breast cancer patient education and support: patient-reported outcomes by survey. J Med Internet Res. 2015;17(7):e188.

23. Bender JL, Jimenez-Marroquin MC, Ferris LE, Katz J, Jadad AR. Online communities for breast cancer survivors: a review and analysis of their characteristics and level of use. Support Care Cancer. 2013a;21(5):1253-63.

24. Bender JL, Katz J, Ferris LE, Jadad AR. What is the role of online support from the perspective of facilitators of face-to-face groups? A multi-method study of the use of breast cancer online communities. Patient Educ Couns. 2013b;93(3):472-9.

25. Falisi AL, Wiseman KP, Gaysynsky A, Scheideler JK, Ramin DA, Chou WS. Social media for breast cancer survivors: a literature review. J Cancer Surviv. 2017;11(6):808-21.

26. Harkin LJ, Beaver K, Dey P, Choong K. Navigating cancer using online communities: a grounded theory of survivor and family experiences. J Cancer Surviv. 2017;11(6):658-69.

27. Platt JR, Brady RR. \#BCSM and \#breastcancer: Contemporary cancer-specific online social media communities. Breast J. 2019. https://doi.org/10.1111/tbj.13576.

28. Sedrak MS, Salgia MM, Decat Bergerot C, Ashing-Giwa K, Cotta $\mathrm{BN}$, Adashek JJ, et al. Examining public communication about kidney cancer on twitter. JCO Clin Cancer Inform. 2019;3:1-6. https://doi.org/10.1200/CCI.18.00088.

29. Wallner LP, Martinez KA, Li Y, Jagsi R, Janz NK, Katz SJ, et al. Use of online communication by patients with newly diagnosed breast cancer during the treatment decision process. JAMA Oncol. 2016;2(12):1654-6.

30. Zhu Y, Cohen SM, Rosenzweig MQ, Bender CM. Symptom map of endocrine therapy for breast cancer: a scoping review. Cancer Nurs. 2019;42(5):E19-30.

31. Milata JL, Otte JL, Carpenter JS. Oral endocrine therapy nonadherence, adverse effects, decisional support, and decisional needs in women with breast cancer. Cancer Nurs. 2018;41(1):E9E18.

32. Benedict C, Hahn AL, Diefenbach MA, Ford JS. Recruitment via social media: advantages and potential biases. Digit Health. 2019;5: 2055207619867223.

33. Owen JE, Bantum EO, Criswell K, Bazzo J, Gorlick A, Stanton AL. Representativeness of two sampling procedures for an intervention targeting cancer-related distress: a comparison of convenience and registry samples. J Behav Med. 2014;37(4):630-41.

34. Condorelli R, Vaz-Luis I. Managing side effects in adjuvant endocrine therapy for breast cancer. Expert Rev Anticancer Ther. 2018;18(11):1101-12.

35. Connor C, Attai D. Adjuvant endocrine therapy for the surgeon: options, side effects, and their management. Ann Surg Oncol. 2013;20(10):3188-93.

36. Ganz PA, Desmond KA, Leedham B, Rowland JH, Meyerowitz $\mathrm{BE}$, Belin TR. Quality of life in long-term, disease-free survivors of breast cancer: a follow-up study. J Natl Cancer Inst. 2002;94(1): 39-49.

37. Ganz PA, Petersen L, Bower JE, Crespi CM. Impact of adjuvant endocrine therapy on quality of life and symptoms: observational data over 12 months from the mind-body study. J Clin Oncol. 2016;34(8):816-24.

38. Mougalian SS, Epstein LN, Jhaveri AP, Han G, Abu-Khalaf M, Hofstatter EW, et al. Bidirectional text messaging to monitor endocrine therapy adherence and patient-reported outcomes in breast cancer. JCO Clin Cancer Inform. 2017;1:1-10. https://doi.org/10. 1200/CCI.17.00015.

39. Pineda-Moncusí M, Servitja S, Tusquets I, Diez-Perez A, Rial A, Cos ML, et al. Assessment of early therapy discontinuation and 
health-related quality of life in breast cancer patients treated with aromatase inhibitors: B-ABLE cohort study. Breast Cancer Res Treat. 2019;177(1):53-60.

40. Lambert LK, Balneaves LG, Howard AF, Chia SK, Gotay CC. Understanding adjuvant endocrine therapy persistence in breast cancer survivors. BMC Cancer. 2018b;18(1):732.

41. Brett J, Boulton M, Fenlon D, Hulbert-Williams NJ, Walter FM, Donnelly $\mathrm{P}$, et al. Adjuvant endocrine therapy after breast cancer: a qualitative study of factors associated with adherence. Patient Prefer Adherence. 2018;12:291-300.

42. Foldi J, O'Meara T, Marczyk M, Sanft T, Silber A, Puszati L. Defining risk of late recurrence in early-stage estrogen receptorpositive breast cancer: clinical versus molecular tools. J Clin Oncol. 2019;37(16):1365-9.

43. Hawley ST, Janz NK, Griffith KA, Jagsi R, Friese CR, Kurian AW, et al. Recurrence risk perception and quality of life following treatment of breast cancer. Breast Cancer Res Treat. 2017;161(3):55765 .

44. Stanton AL, Petrie KJ, Partridge AH. Contributors to nonadherence and nonpersistence with endocrine therapy in breast cancer survivors recruited from an online research registry. Breast Cancer Res Treat. 2014;145(2):525-34.

45. Kahn KL, Schneider EC, Malin JL, Adams JL, Epstein AM. Patient centered experiences in breast cancer: predicting long-term adherence to tamoxifen use. Med Care. 2007;45(5):431-9.

46. Farias AJ, Du XL. Association between out-of-pocket costs, race/ethnicity, and adjuvant endocrine therapy adherence in Medicare patients with breast cancer. J Clin Oncol. 2017;35(1): 89-95.

47. Hershman DL, Tsui J, Wright JD, Coromilas EJ, Tsai WY, Neugut AI. Household net worth, racial disparities, and hormonal therapy adherence among women with early-stage breast cancer. J Clin Oncol. 2015;33(9):1053-9.

48. George GC, Buford A, Hess K, Piha-Paul SA, Zinner R, Subbiah V, et al. Cancer related internet use and online social networking among patients in an early-phase clinical trials clinic at a comprehensive cancer center. JCO Clin Cancer Inform. 2018;2:1-14.

49. Greenup RA, Rushing C, Fish L, Campbell BM, Tolnich L, Hyslop $\mathrm{T}$, et al. Financial costs and burden related to decisions for breast cancer surgery. J Oncol Pract. 2019;15(8):e666-76.

50. Magnezi R, Grosberg D, Novikov I, Ziv A, Shani M, Freedman LS. Characteristics of patients seeking health information online via social health networks versus general internet sites: a comparative study. Inform Health Soc Care. 2015;40(2):125-38.

51. Shneyderman Y, Rutten LJ, Arheart KL, Byrne MM, Kornfeld J, Schwartz SJ. Health information seeking and cancer screening adherence rates. J Cancer Educ. 2016;31(1):75-83.

52. Martinez KA, Kurian AW, Hawley ST, Jagsi R. How can we best respect patient autonomy in breast cancer treatment decisions? Breast Cancer Manag. 2015;4(1):53-64.

53. Armstrong TS. Symptoms experience: a concept analysis. Oncol Nurs Forum. 2003;30(4):601-6.

54. Dodd M, Janson S, Faione N, et al. Advancing the science of symptom management. J Adv Nurs. 2001;33(5):668-76.

55. Salgado TM, Mackler E, Severson JA, Lindsay J, Batra P, Petersen $\mathrm{L}$, et al. The relationship between patient activation, confidence to self-manage side effects, and adherence to oral oncolytics: a pilot study with Michigan oncology practices. Support Cancer Care. 2017;25(6): 1797-807.

56. Cuthbert CA, Farragher JF, Hemmelgarn BR, Ding Q, McKinnon GP, Cheung WY. Self-management interventions for cancer survivors: a systematic review and evaluation of intervention content and theories. Psychooncology. 2019;28(11):2119-40.

57. Easthall C, Barnett N. Using theory to explore the determinants of medication adherence; moving away from a one-size-fits-all approach. Pharmacy (Basel). 2017;5(3):50.
58. Hershman DL, Unger JM, Hillyer GC, Moseley A, Arnold KB, Dakhil SR, et al. Randomized trial of text messaging to reduce early discontinuation of adjuvant aromatase inhibitor therapy in women with early-stage breast cancer: SWOG S1105. J Clin Oncol. 2020. https://doi.org/10.1200/JCO.19.02699 Online ahead of print.

59. Shaverdian N, Yeboa DN, Gardner L, Harari PM, Liao K, McCloskey S, et al. Nationwide survey of patients' perspectives regarding their radiation and multidisciplinary cancer treatment experiences. J Oncol Pract. 2019:JOP1900376. https://doi.org/10. 1200/JOP.19.00376.

60. Schrag D, Hershman DL, Basch E. Oncology practice during the COVID-19 pandemic. JAMA. 2020;323:2005. https://doi.org/10. 1001/jama.2020.6236. Online ahead of print.

61. Wheeler SB, Roberts MC, Bloom D, Reeder-Hayes K, Espada M, Peppercorn J, et al. Oncology providers' perspectives on endocrine therapy prescribing and management. Patient Prefer Adherence. 2016;10:2007-19.

62. Fagerlin A, Zikmund-Fisher BJ, Ubel PA. Helping patients decide: ten steps to better risk communication. J Natl Cancer Inst. 2011;103(19):1436-43.

63. Paladino J, Lakin JR, Sanders JJ. Communication strategies for sharing prognostic information with patients: beyond survival statistics. JAMA. 2019;322:1345. https://doi.org/10.1001/jama.2019. 11533.

64. DiLascio S, Pagani O. Is it time to address survivorship in advanced breast cancer? A review article. Breast. 2017;31:167-72.

65. Ghislain I, Zikos E, Coens C, Quinten C, Balta V, Tryfonidis K, et al. Health-related quality of life in locally advanced and metastatic breast cancer: methodological and clinical issues in randomised controlled trials. Lancet Oncol. 2016;17(7):e294-304.

66. Cardoso F, Senkus E, Costa A, Papadopoulos E, Aapro M, André F, et al. $4^{\text {th }}$ ESO-ESMO international consensus guidelines for advanced breast cancer (ABC 4). Ann Oncol. 2018a;29(8):1634-57.

67. Cardoso F, Costa A, Senkus E, et al. ESO-ESMO $2^{\text {nd }}$ international consensus guidelines for advanced breast cancer (ABC2). Ann Oncol. 2014;25(10):1871-88.

68. Martel S, Bruzzone M, Ceppi M, Maurer C, Ponde NF, Ferreira $\mathrm{AR}$, et al. Risk of adverse events with the addition of targeted agents to endocrine therapy in patients with hormone receptor-positive metastatic breast cancer: a systematic review and meta-analysis. Cancer Treat Rev. 2018;62:123-32.

69. Pemmaraju N, Munsell MF, Hortobagyi GN, Giordano SH. Retrospective review of male breast cancer patients: analysis of tamoxifen-related side effects. Ann Oncol. 2012;23(6):1471-4.

70. Giordano SH. Breast cancer in men. N Engl J Med. 2018;378(24): 2311-20.

71. Wibowo E, Pollock PA, Hollis N, Wassersug RJ. Tamoxifen in men: a review of adverse events. Andrology. 2016;4(5):776-88.

72. Halbach SM, Midding E, Ernstmann N, Würstlein R, Weber R, Christmann $\mathrm{S}$, et al. Male breast cancer patients' perspectives on their health care situation: a mixed-methods study. Breast Care. 2020;15:22-9.

73. Hassett MJ, Somerfield MR, Baker ER, et al. Management of male breast cancer: ASCO guideline. J Clin Oncol Published online 14 February 2020. 2020. https://doi.org/10.1200/JCO.19.03120.

74. Eindhoven DC, Hilt AD, Zwaan TC, Schalij MJ, Willem Borleffs CJ. Age and gender differences in medical adherence after myocardial infarction: women do not receive optimal treatment-the Netherlands claims database. Eur J Prev Cardiol. 2018;25(2):1819.

75. Manteuffel M, Williams S, Chen W, Verbrugge RR, Pittman DG, Steinkellner A. Influence of patient sex and gender on medication use, adherence, and prescribing alignment with guidelines. J Women's Health (Larchmt). 2014;23(2):112-9. 
76. Chen SL, Lee WL, Liang T, Liao IC. Factors associated with gender differences in medication adherence: a longitudinal study. J Adv Nurs. 2014;70(9):2031-40.

77. Cardoso F, Bartlett JMS, Slaets L. Characterization of male breast cancer: results of the EORTC 10085/TBCRC/BIG/NABCG international male breast cancer program. Ann Oncol. 2018b;29(2): 405-17.

78. Sacks CA, Miller PW, Longo DL. Talking about toxicity-"what we've got here is a failure to communicate". N Engl J Med. 2019;381(15):1406-8.
79. Wheeler SB, Spencer J, Pinheiro LC, Murphy CC, Earp JA, Carey $\mathrm{L}$, et al. Endocrine therapy nonadherence and discontinuation in black and white women. J Natl Cancer Inst. 2019;111(5):498-508.

80. Vickers AJ. Validation of patient-reported outcomes: a low bar. J Clin Oncol. 2019;37(23):1990-2.

Publisher's note Springer Nature remains neutral with regard to jurisdictional claims in published maps and institutional affiliations. 